\title{
UTILIZAÇÃO DE TECNOLOGIAS COMO INSTRUMENTO DE APRENDIZAGEM NO ENSINO FUNDAMENTAL: REFLEXÕES SOBRE PRÁTICAS PEDAGÓGICAS
}

\section{ARTIGO ORIGINAL}

FANTI, Renato ${ }^{1}$

FANTI, Renato. Utilização de tecnologias como instrumento de aprendizagem no ensino fundamental: Reflexões sobre práticas pedagógicas. Revista Científica Multidisciplinar Núcleo do Conhecimento. Ano 04, Ed. 08, Vol. 07, pp. 116-134. Agosto de 2019. ISSN: 2448-0959

\section{RESUMO}

No mundo contemporâneo, as tecnologias têm provocado mudanças nas formas de comunicação, trabalho, consumo, ensino e aprendizagem. O mundo virtual é parte integrante da vida dos cidadãos e a mobilidade proporcionada pelo uso de dispositivos móveis - que disponibilizam informação a qualquer lugar e a qualquer hora - traz um desafio para as práticas e ambientes educacionais, estruturados em disciplinas que muitas vezes não se comunicam, em tempos de aulas definidos e centrados na figura do professor como principal organizador dos conteúdos. O presente artigo teve como objetivo fazer um reflexão da situação atual da utilização de tecnologias no ensino fundamental I, em especial para investigar se o fato de o professor ser um usuário das tecnologias, garante em sua prática docente uma mediação desses recursos de forma a promover um ambiente colaborativo, de compartilhamento e participação ativa do aluno na construção dos conhecimentos. Utilizou-se como referencial teórico um levantamento de artigos, teses e dissertações sobre tecnologias no contexto

1 Mestre em Filosofia (PUC-SP) - Pós Graduado Latu Sensu em Pedagogia (FUTURA) - Graduado em Pedagogia (UNINTER-PR) - Graduado em Filosofia (São Bento-SP). 
educacional na SciELO e na Biblioteca Digital Brasileira de Teses e Dissertações. Valeu-se também de uma reflexão sobre a práticas docentes de colegas e do autor.

Palavras-Chave: Currículo, tecnologias educacionais, metodologias ativas, Ensino Fundamental I.

\section{INTRODUÇÃO}

O interesse relativo às contribuições da tecnologia para a educação começaram enquanto aluno do ensino fundamental nos longínquos anos 1980, quando foram apresentados conceitos básicos de linguagem computacional LOGO ${ }^{[2]}$, dado que despertou o interesse por informática. No decorrer de muitos anos o autor mantevese sempre dentro de instituições escolares, e já nos primeiros anos universitários, também como professor (cuja primeira graduação foi em Letras, em seguida Filosofia até chegar à Pedagogia), que o fez observar atentamente como os educadores e as instituições escolares fizeram o acompanhamento da evolução tecnológica e a preparação dos professores para a utilização em suas práticas pedagógicas.

As salas de informática das instituições escolares, por muito tempo foram sinônimo de modernização e aposta em melhorias nas práticas educacionais, mas é importante ressaltar que mesmo muito esforço das instituições não é suficiente se trabalhar a tecnologia como um fim em si mesmo e não trouxer para a sala de aula uma dinâmica diversificada na relação professor/aluno/conhecimento, isso significa que não é suficiente investir em tecnologia sem uma contínua reflexão sobre as possibilidades e os avanços que elas proporcionam em processos educacionais.

As principais dificuldades enfrentadas pelos educadores no início da informática educacional, foi não ter a sua disposição, seja pelo custo ou pela escassez, softwares educacionais que atendessem aos seus interesses, juntando-se com o temor de ser substituído pela máquina, de o aluno saber mais do que ele, de ele ter que levar os alunos para o laboratório e assim ser um "professor moderno", mesmo sem ter a mínima noção do que fazer com os alunos frente às máquinas, porém a realidade do 
desenvolvimento das tecnologias mostrou que os avanços na área foram cada vez mais rápidos e profundos.

Diante da impossibilidade de os habitantes dos centros urbanos e suas práticas profissionais ficarem alheios às demandas tecnológicas, os professores e as instituições escolares não poderiam ser uma exceção.

O avanço das tecnologias foi acelerado, alguns temores foram extintos e ocupados frequentemente por outros. Estamos inseridos em uma sociedade de transformações, de abundante informação de acesso fácil e nossa perplexidade não estanca diante da rapidez da evolução tecnológica e sem saber ao certo de que modo elas podem favorecer os processos educacionais.

O maior desafio é entender como mediar a aquisição do conhecimento de uma geração nascida na cultura digital, de uma geração conectada que tem disponível informação em qualquer lugar e a qualquer hora.

Os dispositivos móveis conectados à internet estão cada vez mais presentes na vida das pessoas. A facilidade que se tem em adquirir um Smartphone ou um tablet, é revelado pelos dados da pesquisa do IDC ${ }^{[3]}$ que mostra um crescimento de $147 \% \mathrm{em}$ 2017 na venda de Smartphone em relação à 2015. Quanto aos tablets, as vendas cresceram 83\% em 2017, superando desde 2013 os Desktops.

Nesse universo conectado estão os professores e as escolas que, diferindo em graus de habilidade, fazem uso dessas tecnologias. Isso porque, utilizar as tecnologias em contextos educacionais vai muito além de ser um mero usuário das mesmas, constituise de uma reciclagem cultural da instituição, de maneira que as tecnologias da informação e da comunicação trabalhem a serviço da contínua formação de alunos/cidadãos preparados para participar da sociedade contemporânea. Segundo MAURIO e ORNUBIA (2010, p.118), "trata-se de aprender a dominar e a valorizar uma nova cultura de aprendizagem". Novas tecnologias trazem exigências de novas posturas pedagógicas. 
Diante desse cenário, definimos a questão do presente artigo da seguinte forma: Como os professores utilizam as tecnologias em contextos educacionais e quais concepções revelam?

O objetivo, portanto, é refletir se um docente com experiência na utilização de tecnologias, traz a garantia em sua prática docente de uma mediação desses recursos de maneira a promover um ambiente profícuo em cooperação e ativa participação do aluno na composição dos conhecimentos.

\section{A RELAÇÃO PROFESSOR/CONHECIMENTO}

As escolas não são instituições isoladas no tempo e no espaço, estão inseridas em uma sociedade, na sua organização, na sua cultura, na sua estrutura e na sua história. Assim sendo, o ensino que nela se pratica "deveria servir para dar sentido ao mundo que rodeia os alunos, para ensiná-los a interagir com ele e a resolverem os problemas que Ihes são apresentados" (COLL; MORNERO, 2010, p.39). Ao professor, torna-se fundamental saber que tipo de indivíduo pretende formar, pois disso dependem as escolhas dos conteúdos que ensinam, das metodologias e das atitudes que assumem diante dos alunos.

A sala de aula é um organismo vivo, complexo, imprevisível e mutante. Segundo Gómez (1998, p. 74) "a base da eficácia docente encontra-se no pensamento do professor capaz de interpretar e diagnosticar cada situação singular e de elaborar, experimentar e avaliar estratégias de intervenção". E não em adotar modelos universalmente válidos de como ensinar. Uma mesma estratégia de ensino pode provocar resultados completamente diferentes nos alunos de uma mesma sala, porque os alunos não são receptores passivos de conhecimento e os processos de aprendizagem são particulares, singulares e subjetivos.

Para Zabala (1998) entende que os indivíduos não estão parcelados em compartimentos estanques, em capacidades isoladas. Freire (1996), ensinar não é transferir conhecimentos, mas criar possibilidades para sua própria produção ou sua construção. Hernández (2006), por sua vez, defende que uma visão integrada da 
educação deve favorecer a criação de experiências de aprendizagem com sentido envolvendo a comunidade educativa, apaixonadamente no processo de aprender ${ }^{[4]}$ ou ainda transformar uma aprendizagem rotineira em uma autêntica experiência de vida.

Zabala (1998) defende que a chave de todo ensino está nas relações que se estabelecem entre os professores, alunos e conteúdos de aprendizagem e que as atividades são um meio para mobilizar a trama de comunicações que pode se estabelecer em classe.

Tanto os alunos quanto os professores são ativos processadores de informação e subjetivos construtores de significados (GÓMEZ 1998) e precisam estar motivados para realizar o esforço necessário para alcançar as aprendizagens.

A sala de aula está repleta de situações de aprendizagem, cabendo ao professor lançar mão de estratégias para atender às diversas formas de aprender dos alunos. Nem todos aprendem da mesma forma, no mesmo ritmo e fazem as tarefas do mesmo jeito. Para atender a diversidade de uma sala de aula, o planejamento do professor precisa prever um amplo leque de atividades, intencionalmente planejadas, que ajudem a resolver a diferentes situações complexas que a sala de aula apresenta. É necessário diversificar as atividades, com diferentes opções ou níveis possíveis de realização, assim como intervir de maneiras diferentes no auxílio às dificuldades dos alunos.

É importante que o aluno participe e entenda os objetivos das atividades, entenda o porquê das tarefas propostas e responsabilize-se pelo processo de construção do conhecimento. É preciso examinar a disposição, os conhecimentos prévios (AUSUBEL), esquemas de assimilação (PIAGET, 1971), internalização de instrumentos e signos (VYGOTSKY, 1987), o conhecimento experiencial ou extraescolar que os alunos adquirem em sua vida paralela à escola (GÓMEZ, 1998), enfim, as capacidades de cada aluno em relação à tarefa proposta:

Quer dizer, apresentar com os conteúdos que já sabem, com seu mundo experiencial, estabelecendo, ao mesmo tempo, certas propostas de 
atuação que favoreçam a observação do processo que os alunos seguem para poder assegurar que seu nível de envolvimento é o adequado. Sem esse ponto de partida, dificilmente será possível determinar os passos seguintes (ZABALA, 1988, p.95)

Um aspecto central da teoria de Vygotsky (1987) é a importância de uma intervenção pedagógica deliberada e intencional, que considere o aluno como sujeito ativo, que se relaciona com um ambiente ativo e estruturada pela cultura, e que traz como contribuição a sua subjetividade para este ambiente. Para ele:

o sujeito não percorreria caminhos de desenvolvimento sem ter experiências de aprendizagem e o papel do professor, como mediador dessas experiências, é de fundamental importância (1987. p.16)

A escola possui um papel importante para o desenvolvimento de formas mais elaboradas de pensamento, portanto, deve saber utilizar ao máximo os recursos que levem a esse fim.

Trabalhar a partir de representações dos alunos consiste em permitir que sejam valorizados. O importante é dar a eles regularmente direitos na aula, interessar-se por essas representações, tentar compreender suas raízes e sua forma de coerência, "não se surpreender se elas surgirem novamente, quando as julgávamos ultrapassadas" (PERRENOUD, 2000, p.28).

Para levar em consideração as colaborações dos educandos, juntamente com um clima apropriado, é necessário propor atividades que fomentem o diálogo, que os permitam formular questões e reciclar o conhecimento prévio, fundamental para estabelecer uma relação entre conteúdos.

A mediação do professor deve apoiar-se nas características individuais dos alunos, através de uma interação que permita ao docente, na medida do possível, acompanhar os processos realizados pelos educandos em sala de aula, fazendo as intervenções diferenciadas quando necessárias. Em síntese, trabalhar com educandos provenientes de diversos contextos culturais e sociais e com diferenciada 
nivelação em relação a aprendizagem com a intenção de oferecer as mesmas garantias de aprendizagem para cada indivíduo.

O ensino direto de conceitos é impossível e infrutífero. Um professor que tenta fazer isso geralmente não obtém qualquer resultado, exceto o verbalismo vazio, uma repetição de palavras pela criança, semelhante a de um papagaio, que simula o conhecimento de um conceito correspondente, mas que na realidade oculta um vácuo. (VYGOTSKY, 1987, p.72).

Segundo Zabala (1998, p.127), "a aprendizagem por mais que se apoie num processo interpessoal e compartilhado é sempre, em última instância, uma apropriação pessoal, uma questão individual".

O processo de aprendizagem é uma questão de aprimoramento individual, no qual cada educando progride com um ritmo diferenciado.

A própria sociedade contemporânea impõe desafios para a prática educativa e exige um olhar cuidadoso do educador sobre sua atuação docente, pois o conhecimento não é uniforme para os alunos que desde muito cedo manipulam ferramentas tecnológicas de comunicação e informação; os acessos que os educandos têm à informação são muito diversos de há alguns anos. Portanto, existe uma necessidade premente de uma ação pedagógica que transforme a relação do aluno com a informação e o conhecimento.

\section{ENSINAR COM AS TECNOLOGIAS: REALIDADE - NECESSIDADE - DESAFIO}

No caso da educação, a solução não pode ser sentir saudades dos tempos passados, da velha escola, muito menos, como alguns pretendem, fazer o possível para que ela volte. Mas também não basta fazer pequenos ajustes, colocar band-aids em nossas aulas e em nossos hábitos docentes, introduzindo os computadores e alguma outra 
tecnologia para continuar desenvolvendo os mesmos currículos [...] chega um momento em que o acúmulo de pequenos ajustes nas formas culturais para aprender e ensinar não é mais suficiente e é necessário fazer uma verdadeira reestruturação, uma mudança radical das estruturas e hábitos anteriores. Mas também sabemos que essa reestruturação somente será possível quando tivermos construído uma teoria ou modelo alternativo que de alguma maneira integre o que havia antes. É daí que surge a perplexidade atual de nosso sistema educacional, que navega entre a crise constante e a introspecção, cada vez mais consciente de que o que havia antes não vale mais, mas sem saber muito bem o que é o novo, porque conhecemos somente os primeiros brotos, o germe dessas formas de pensar, de comunicar-se: em resumo, de conhecer (MONEREO; POZO, 2010, p.97).

No trecho destacado acima, os autores afirmam que o sistema de ensino navega entre a crise de saber que o modelo anterior não vale mais porém, sem saber muito bem o que é o novo. Segundo Bauman (2007, p.121) "os tempos são líquidos porque tudo muda muito rapidamente, nada é feito para durar, para ser sólido". De fato, a sociedade vem passando por transformações culturais, mercadológicas, econômicas e sociais de forma surpreendente graças às tecnologias, que modificam a forma de produção e disseminação de informações da vida em sociedade.

Educar nessa e para essa sociedade é ser desafiado a rever concepções, formas de ensinar, estratégias metodológicas e a relação com os conteúdos de ensino.

A discussão sobre a importância das tecnologias na educação não é recente e, embora grande parte dos educadores reconheça que não dá para desconsiderar a presença delas nas salas de aula, a contribuição para os processos de ensino e aprendizagem e os avanços em seu uso em abordagens pedagógicas, ainda causam desconforto e opiniões muito controvertidas, como a polêmica discussão sobre o uso de telefone celular nas salas de aula[5]. 
Considerando a evolução do pensamento pedagógico e das tecnologias, elas deveriam ser encaradas como potencializadoras do processo de ensino e aprendizagem. Afinal, qual ambiente hoje é mais provocador, desafiador e fascinante para os alunos, do que aqueles proporcionados pelas tecnologias digitais?

Se entendermos que a escola quer estar em consonância com a sociedade, e que as práticas de ensino devem considerar o contexto social e cultural dos alunos, não é possível pensar o cidadão do século XXI sem pensar em um indivíduo incluído digitalmente e que saiba fazer uso das possibilidades que the são oferecidas. A escola é um lugar privilegiado para oferecer condições cognitivas para que o sujeito saiba fazer uso do mundo de informações disponíveis na rede. A educação deveria estar "muito mais próxima do universo cultural em que estão e atuam os sujeitos que fazem uso dessas tecnologias" para além dos espaços formais de aprendizagem (SANTOS, 2001).

Os recursos tecnológicos deveriam ajudar a construir "conhecimentos por tornarem acessíveis operações ou manipulações impossíveis ou muito desencorajadoras" se reduzidos ao lápis a ao papel (PEERENOUD, 2000, p.133).

Deveriam possibilitar o estabelecimento de relações que não seriam possíveis de outra forma ou seriam muito mais significativas com ela.

É evidente que os docentes precisam estar preparados para ensinar na sociedade do conhecimento. Não enxergar o potencial das tecnologias ou não saber como utilizálas a favor da educação é como fechar os olhos para a realidade da sociedade em que os alunos estão inseridos. Porém, uma atividade mediada pela tecnologia deve sempre estar permeada por propostas que evidentemente melhorem as aulas e traduzam-se por aprendizagens significativas.

Se entendermos que a aprendizagem é um processo de construção pessoal e que para que ela ocorra e altere as estruturas cognitivas do indivíduo, o ambiente deve ser provocador e as experiências possibilitadas por esse ambiente ricas e significativas, não há como ignorar a influência que as tecnologias exercem sobre a vida dos nativos 
digitais $^{[6]}$. Por que então, os professores preferem ignorá-las ou usá-las de forma tão trivial? Seria certo talvez afirmar que quanto mais o professor se sente familiarizado com as questões técnicas, mais habilidoso for ao uso de tecnologias, mais conseguirá tirar proveito de seus recursos ou será que sem o conhecimento técnico será possível implantar soluções pedagógicas inovadoras?

Sobre a referida questão, VALENTE (2002, p.04) defende que o "domínio das técnicas acontece por necessidades e exigências do pedagógico" e as novas possibilidades técnicas criam "novas aberturas para o pedagógico", constituindo uma verdadeira espiral de aprendizagem ascendente na sua complexidade técnica e pedagógica.

Allegretti e Jimena afirmam que as dificuldades que os professores apresentam em incorporar as tecnologias remete a três questões básicas:

[...] a necessidade de o professor ter consciência de que ele deve ser a única fonte de informação do aluno; de que a apropriação de um novo recurso tecnológico requer o conhecimento da potencialidade técnica e comunicacional deste recurso, e de reconhecer em que medida o mesmo se aplica à abordagem pedagógica utilizada. (2007. p.4)

É necessário que reflitamos acerca dos instrumentos facilitadores para uma efetiva diferenciação e uma verdadeira individualização dos processos formatórios, ou seja, um acesso democrático aos conteúdos de formação. Pois ao entendermos que o modo de produção das aprendizagens são processos individuais, o uso de tecnologias em classe teriam a função de de auxiliar o docente a responder a atividades particularizadas, de maneira que a aprendizagem seja efetivada através das capacidades e dos conhecimentos prévios de cada discente, permitindo assim, ao professor, salientar os diversos níveis de conhecimento de cada educando, levando em consideração a diversidade da sala, com as identificações dos desafios necessários e das consequentes intervenções. Ao mesmo tempo, não podemos deixar de considerar a construção coletiva e as trocas de experiência, como salienta Lèvy (1999, p.7): 
Em geral me consideram um otimista. Estão certos. Meu otimismo, contudo, não promete que a Internet resolverá, em um passe de mágica, todos os problemas culturais e sociais do planeta. Consiste apenas em reconhecer dois fatos. Em primeiro lugar, que o crescimento do ciberespaço resulta de um movimento internacional de jovens ávidos para experimentar, coletivamente, formas de comunicação diferentes daquelas que as mídias clássicas nos propõem. Em segundo lugar, que estamos vivendo a abertura de um novo espaço de comunicação, e cabe apenas a nós explorar as potencialidades mais positivas deste espaço nos planos econômico, político, cultural e humano.

Tecnologia traz flexibilidade, amplia o espaço da sala de aula e leva os professores a reconsiderar novas formas de produzir as aprendizagens. O currículo se amplia e passa a ser o que vivemos, as relações que mantemos ou desejamos, os saberes que construímos ao nos apropriarmos da informação, "transformando-a em conhecimento quando a transferimos a situações novas ou o papel que desempenhamos em nosso ambiente social" - como trama de relações e representações, não como espaço físico (HERNÁNDEZ, 2006, p.51). Nessa perspectiva, o entendimento sobre o currículo precisa ser olhado para além do conjunto de conteúdos que precisam ser ensinados e pré-estabelecidos, até porque a escola já não é mais o único espaço para se ensinar e aprender. "Se currículo é entendido como construção cultural, social, produzida na escola pela escola, mas em comunicação com outras redes comunicativas" (SANTOS, 2011). Conhecimento é algo também tecido com outro e em rede.

\section{COMPETÊNCIAS PARA SE ENSINAR COM TECNOLOGIA}

[...] a incorporação das TIC às atividades de sala de aula não é, necessariamente, e nem em si mesma, um fator de transformação e inovação nas práticas educativas. Ao contrário, as TIC revelam-se antes como um elemento reforçador das práticas educativas existentes, o que equivale a dizer que só reforçam ou promovem inovação quando se inserem em uma dinâmica de mudança educacional mais ampla (COLL, 2007, p.124) 
Não há consenso em torno das competências que os professores devem adquirir para integrar as tecnologias nas suas práticas, pois está em questão a forma como se entende a dinâmica da integração entre professores, alunos e conteúdo.

Se cabe à escola o papel de formar cidadãos críticos e capazes de atuarem em uma sociedade em entornos tecnológicos em constante movimento, esse papel requer mudanças na relação entre ensinar e aprender e exige dos professores habilidades e competências em busca de novas estratégias para a incorporação das tecnologias digitais em sua aula. A quantidade e qualidade das informações e a rapidez das mudanças proporcionadas pela sociedade digital desafia professores a rever suas práticas e esforçar-se para entender e integrar as tecnologias no processo de ensino e aprendizagem.

Centrar o ensino em uma dimensão puramente tecnológica seria:

[...] assumir em menor ou maior grau, que a realidade é objetiva e que a finalidade do ensino é apresentá-la o mais objetivamente possível, transmitir essa realidade e modificar a conduta dos alunos de acordo com o que pretende transmitir. Consequentemente, o propósito do ensino é facilitar a tranferência do conhecimento de um especialista para um aprendiz. MAURI e ORNUBIA (2010, p.118)

Mauri e Ornubia (2010), ao falar sobre as competências que os professores devem adquirir para conseguir integrar as tecnologias na educação, traçam um panorama do perfil, condições e competências do professor, afirmam que é necessário dominar e valorizar uma "nova cultura de aprendizagem". Segundo os autores citados, essas competências são caracterizadas como:

- A capacidade que professores e alunos devem ter para procurar, selecionar e interpretar informações, atribuindo significado e sentido;

- Capacidade de gestão do aprendizado, do conhecimento: formação permanente; 
- Aprendizagem para conviver com diversos pon tos de vista, com a relatividade das teorias.

Consideraremos então, que uma atuação competente supõe dispor dos conhecimentos e das capacidades necessárias para identificar e caracterizar contextos relevantes de atividade, sob duas vertentes:

1. Dimensão tecnológica centrada em si mesma como fator determinante da aprendizagem;

2. Como elementos mediadores, interativos, centrados na construção do conhecimento.

Quanto ao primeiro aspecto, a dimensão tecnológica centrada em si mesma, o rendimento dos alunos está diretamente relacionado à introdução das tecnologias, no acesso aos computadores, às informações disponíveis e à elaboração de materiais utilizando as tecnologias. Assim, tendo à sua disposição recursos tecnológicos na sala de aula, no laboratório de informática ou nos dispositivos dos próprios alunos, a competência do professor está em valorizar, conhecer, dominar tecnicamente as ferramentas e ser capaz de usar as tecnologias para aproximá-las das necessidades dos alunos, selecionando o que é trivial, nas palavras dos autores: "maneira mais objetiva possível, aceitando, além disso, a hipótese de que todos os aprendizes usam o mesmo tipo de critério e os mesmos processos para aprender" (MAURI e ORNUBIA. 2010, p.118).

Em se tratando do segundo aspecto, uma dimensão centrada na construção do conhecimento, a competência do professor está na sua capacidade para identificar contextos relevantes de atividades que promovam a individualidade adequada do aluno, facilitando a ele a exploração do ambiente tecnológico. O foco sai exclusivamente das possibilidades técnicas e centram-se nas atividades que colocam os alunos como protagonistas. As atividades mediadas pelas TIC precisam dar sentido e significado ao conteúdo da aprendizagem e estar a serviço do professor e do aluno. 
A integração das tecnologias nas escolas sempre está associada ao uso que os professores fazem dela. Considerando que as tecnologias evoluem rapidamente, envolver-se em educação continuada para adquirir competências necessárias para seu uso é trivial.

\section{A MASSIFICAÇÃO DAS TECNOLOGIAS E A RELAÇÃO DO PROFESSOR COM O SABER}

[...] o que precisamos reter em nossas mentes é que vivemos em um tempo em que não há mais lugar para a nostalgia. A velocidade tomou conta do mundo e se há uma área da ação humana que não permite que fiquemos à janela vendo a banda passar, essa área é a da educação. (SANTAELLA, 2013, p.126)

É um discurso recorrente e até certo ponto óbvio que, apesar de todo o encantamento que as tecnologias proporcionam, o mais importante é o uso que se faz delas e como elas podem ajudar a melhorar os processos de ensino e aprendizagem. Diante dos inúmeros movimentos que surgiram na informática educacional, os professores têm se posicionado de diferentes formas: a ideia que a tecnologia um dia poderia substituilo ao temor de não dominá-la tanto quanto o aluno, o professor tem sido desafiado constantemente e talvez o maior desafio seja lidar com as tecnologias móveis, interativas, acessíveis, conectadas com o planeta e que estão cada vez mais presentes na vida dos cidadãos. Não há saída, como afirma Santaella (2013, p.20) "os riscos têm que ser assumidos, devemos sumariamente evitar o sonambulismo tecnológico cujo lema é deixar passar para ver como é que fica".

É correto afirmar que o "mundo encolheu ao mesmo tempo em que a percepção do homem expandiu" (ALLEGRETTI, 2012, p.26). A internet nos possibilita encontrar respostas imediatas para os mais variados temas. Acessar informação a qualquer momento e em qualquer lugar está cada vez mais fácil. Os computadores estão cada vez mais leves, rápidos, sem fios e mais conectados como nunca, a exemplo dos smartphones. 
Isso nos faz pensar o quanto esses dispositivos estão presentes na vida dos cidadãos e também nas escolas, nas mãos de alunos e professores. Esses aparelhos agregam funções de voz e dados, compatíveis com os desktops, expressando convergência ${ }^{[7]}$ das mídias, isto é, ao mesmo tempo em que é um telefone, acessa a internet, é máquina fotográfica, filmadora, GPS entre tantas funções. Em Gabriel (2013, p.15) encontramos um interessante afirmação:

A banda larga de internet permitiu a importante mudança de "estar conectado" para "ser conectado". "Estar" conectado significa que você eventualmente entra e sai da internet, [...] "Ser" conectado significa que parte de você está na rede - você vive em simbiose com ela.

Então, o que fazer para que isso não seja uma ameaça para as aulas centradas no professor, sem que seja preciso lançar mão de amparos legais? Como usar o potencial dessa tecnologia a favor de uma aula melhor?

As tecnologias têm sido capazes de instigar alunos e professores a fazer novas descobertas e ter um novo olhar sobre os processos de aprendizagem.

A flexibilidade permitida pelo uso dos dispositivos móveis ${ }^{[8]}$ que disponibilizam comunicação e informação em qualquer lugar e a qualquer hora, traz consigo o conceito de ubiquidade, isto é, estar em todas as partes em qualquer tempo, onipresente:

[...] o desenvolvimento tecnológico me levou à convicção de que a condição contemporânea de nossa existência é ubíqua. Em função da hipermobilidade, tornamo-nos seres ubíquos. Estamos, ao mesmo tempo, em algum lugar e fora dele. Tornamo-nos intermitentemente pessoas presentes-ausentes. Aparelhos móveis nos oferecem a possibilidade de presença perpétua, de perto ou de longe, sempre presença. Somos abordados por qualquer propósito a qualquer hora e podemos estar em contato com outras pessoas quaisquer que sejam suas condições de localização e afazeres no momento, o que nos 
transmite um sentimento de onipresença. Corpo, mente e vida ubíquas. Sem dúvida isso traz efeitos colaterais, certo estado de frenesi causado pelo paradoxo da presença e ao mesmo tempo da reviravolta constante nas várias condições físicas, psicológicas e computacionais. (SANTAELLA, 2013, p.16)

As tecnologias móveis trazem enormes desafios para os currículos escolares estruturados em disciplinas estanques, em tempos de aula definidos, em registros baseados no lápis e papel, em aulas centradas na figura do professor como "provedores primordiais da educação" (GABRIEL, 2013).

Em outra passagem, Santaella destaca que:

[..] a ecologia midiática hipermóvel e ubíqua afeta, sobretudo, a cognição humana. Ao afetara cognição, produz repercussões cruciais na educação. Novas maneira de processar a cultura estão inteiramente conectadas a novos hábitos mentais que, segundo o pragmatismo, desaguam em novos modos de agir. os desafios apresentados por essas emergências deveriam colocar sistemas educacionais em estado de prontidão.(2013, p.18-19).

Isso nos faz refletir que, quando o aluno pode buscar a informação e o conhecimento em qualquer outra fonte que esteja ao seu alcance, a qualquer momento, inclusive enquanto a aula acontece, a relação com o conhecimento passa a ser outra. Quando o aluno passa a ter acesso a qualquer informação, o professor deixa de exercer a função de "filtro de conteúdo" (GABRIEL, 2013). O professor precisa pensar em como as tecnologias poderão ajudar seus alunos a serem pessoas autônomas em uma sociedade digital, buscando novas formas de ensinar a pensar, analisar, criar, associar informações e aplicar; precisa ensinar o aluno a aprender.

O professor precisa estar consciente de que não é mais detentor do saber, pois compartilha essa capacidade com hipertextos e com tecnologias que facilitam e permitem o acesso em qualquer lugar e momento. 
As maneiras de ensinar já não atendem as necessidades de uma geração conectada, essa geração não precisou aprender a dominar as máquinas; nasceu com TV, computador e comunicação rápida. "Eles usam uma linguagem veloz, fazem tudo ao mesmo tempo e vivem mudando de lugar" (LOIOLA, 2009, p.17).

Ao mesmo tempo em que estudam, conseguem ler notícias na internet, checar a página na rede social, ouvir música e ainda prestar atenção na conversa entre os colegas ao lado. Para eles, a velocidade é outra. Os resultados precisam ser mais rápidos e os desafios constantes. Não é possível então, que na escola o aluno ainda deva apenas escutar uma aula.

Para os nativos digitais o mundo sempre foi assim, tecnológico, rápido, no qual uma infinidade de coisas acontecem ao mesmo tempo, em que se começa em uma coisa e se termina em outra, vida conectada o tempo todo.

No entanto, toda esta miríade de informações disponível nos ambientes virtuais não traz garantia de aprendizagem se o aluno não souber buscá-las, selecioná-las, relacioná-las enfim. Nesse sentido, GABRIEL (2013, p.104) afirma que "a principal habilidade passa a ser como escolher a informação correta em cada situação, como validar, organizar, extrair e solucionar problemas", ou seja, aprender a aprender é importante e o papel do professor como organizador é fundamental nesse processo, auxiliando os alunos a escolherem os filtros corretos para organizar suas experiências e os capacitando para organizar e atribuir sentido e significado à informação tão facilmente adquirida.

Professores e alunos precisam buscar novas formas de pensar e de conduzir o complexo processo de ensino e aprendizagem. A aprendizagem acontece também, através da cooperação entre iguais, por um processo de prática continuada do "aprender fazendo". Os professores deveriam aproveitar as habilidades dessa geração a favor de uma aprendizagem significativa.

Para finalizar este trecho, citaremos SILVA (2018): 
Diante no novo contexto sociotécnico, a docência interativa requer a morte do professor narcisicamente investido de poder. Expor sua opção crítica à intervenção, à modificação, requer humildade para aprender com a dinâmica comunicacional das interfaces online e dialogar com o novo espectador. Esse desafio supõe a formação continuada e específica.

\section{METODOLOGIA}

A opção metodológica que utilizamos para atingir o objetivo foi a pesquisa exploratória, através de levantamento bibliográfico e análise de exemplo de prática pedagógica.

Para a fundamentação teórica, procuramos utilizar clássicos da filosofia da tecnologia, entre eles destacamos Zygmunt Bauman, Pierre Lèvy assim como as importantes reflexões da professora Lucia Santaella, em paralelo à também clássicos da reflexão pedagógica, incluindo Lev Vygotsky, Paulo Freire e Jean Piaget e seus comentadores.

Com o objetivo de considerar a atualidade dos comentários relevantes ao tema e diante de tão prolífica produção acerca do mesmo, procuramos delimitar a pesquisa em artigos diretamente ligados às palavras chave: Currículo, Tecnologias Educacionais, Metodologias Ativas e Ensino Fundamental I, e circunscrever no período entre o final da primeira década do século XXI e a atualidade, contando com pesquisas em revistas e websites especializados.

No que se refere às práticas supracitadas, procuramos estabelecer um diálogo com colegas de universidades e professores experientes que passaram e ainda estão passando por mudanças nas práticas que até antão eram consideradas consolidadas.

\section{CONSIDERAÇÕES FINAIS}

- Utilização De Tecnologias Implica Mudança De Postura Prática 
É relativamente comum encontrarmos professores que apenas reproduzem práticas "antigas" através de novas ferramentas tecnológicas: ou seja, em vez de escrever no caderno digitar em um editor de texto; em vez de consultar um livro, o fazem na Internet; no lugar de aplicar uma atividade reproduzida em uma lousa ou impressa em cópias, disponibilizar através de um arquivo digitalizado. Resguardadas as economias de tempo e a facilidade que isso proporciona, não se avança para utilizar o potencial das tecnologias para promover discussões, atividades colaborativas, trocas entre comunidades de aprendizagem, entre professores e alunos entre muitas outras possibilidades que levam em conta a atividade intelectual construtiva do aluno.

Portanto, conhecer bem as tecnologias e ser usuário constante delas, características de todos os professores com os quais o autor conviveu, não significa necessariamente tornar os contextos de aprendizagem melhores e mais significativos. Na perpectiva de Vygotsky, é imprescindível a intervenção pedagógica deliberada e intencional, que considere o aluno como sujeito ativo, que se relaciona com um ambiente ativo e estruturado pela cultura, e que traz como contribuição a sua subjetividade para este ambiente. Ao nosso entendimento, o professor que não consegue ter clareza de um sujeito ativo que interage com um ambiente ativo, modificando-o e modificando a si próprio nessa interação, dificilmente conseguirá utilizar a tecnologia que não seja para reproduzir velhas práticas com um ar de modernidade.

Sejam as concepções desses professores tradicionais ou socio construtivistas, todos têm muito claro que não são mais os únicos filtros e selecionadores de conteúdo, a principal fonte de informação, embora isso possa ainda trazer certo desconforto para alguns. Temos atualmente disponível um verdadeiro mar de informação de fácil acesso.

Assim sendo, os professores têm consciência de que a sociedade contemporânea traz novas competências para seu papel. As tecnologias exigem que ele desenvolva essas competências, que abarquem a formação continuada, leitura crítica e catalisação de informação útil para auxiliar o aluno a adquirir habilidades indispensáveis que thes permita compreender o que fazer com as informações que estão a sua disposição a qualquer tempo, lugar e de muitas formas diferentes, sendo capaz de gerar 
conhecimento. Isto é, estar pronto para lidar com uma escola que se expande a partir do momento que o mundo virtual passa a integrar o ambiente de ensino e aprendizagem.

O professor precisa perceber-se como mediador e não mais como o único detentor e transmissor do conhecimento, ser um bom usuário de tecnologias, não é garantia de usar os ambientes virtuais de forma a gerar aprendizagens significativas. O professor pode usar as tecnologias e a aula continuar a ser distribuição de conteúdos empacotados para assimilação e repetição ou a velha pedagogia da transmissão transvestida de era digital.

Antes, existe a necessidade de uma reflexão sobre as concepções de educação que embasam a sua prática pedagógica, porque ele reflete a maneira como as tecnologias são utilizadas em seu contexto de ensino. Contamos com diversas práticas pedagógicas e uma variedade de estratégias que traduzem a importância do uso das tecnologias para a sala de aula como elementos potencializadores e não somente como forma complementar.

Não cabe mais diante de uma sociedade da informação e do conhecimento, de um mundo tão aberto, um professor meramente transmissor de saberes; antes cabe um professor que auxilie o aluno a selecionar e organizar tanta informação, a ligar os saberes e dar-Ihes sentido, como lembra MORIN (2001).

Podemos então, responder a questão que nos propusemos da seguinte maneira: mediar atividades de aprendizagem com as tecnologias onde se busca um contexto rico e diverso de interações e atividades que possam promover aprendizagem significativa, não depende apenas de um professor que usa diversos dispositivos e as domina com facilidade, mas depende fundamentalmente, da forma como os professores entendem o processo de ensino e aprendizagem.

Acreditamos que este texto possibilitou uma primeira reflexão sobre um tema tão atual e importante para uma prática pedagógica significativa e possa servir de inspiração para o aprofundamento do mesmo. 


\section{REFERÊNCIAS}

ALLEGRETTI, S; PENA JIMENEZ, M Dolores. Ação Docente, Tecnologia e Ambiente Virtual de Videoconferencia.VI Congresso Internacional Virtual Educa 2007. São José dos Campos. SP.

BAUMAN, Zygmunt. Tempos líquidos. Rio de Janeiro, Zahar, 2007.

COLL, César. Aprender e ensinar com as TIC: expectativa, realidade e potencialidade. In: CARNEIRO, Roberto; TOSCANO, Juan Carlos; DIAZ, Tamara (orgs.). Os desafios das TIC para as mudanças na educação. Madrid/São Paulo, OEI \& Fundação Santiliana, 2007.

FREIRE, Paulo. Pedagogia da Autonomia: saberes necessários para a prática educativa. São Paulo, Paz e Terra, 1996.

GABRIEL, Martha. Educ@ar: e (r)evolução digital na educação. São Paulo, Saraiva, 2013.

GOMÉZ, A.I. Ensino para a compreensão. In: SACRISTÀN, J. Compreender e transformar o ensino. Porto Alegre, ArtMed, 1998.

HERNANDEZ, Fernando. Por que dizemos que somos a favor da educação se optamos por um caminho que deseduca e exclui? In: Tecnologias para transformar a educação. Porto Alegre, ArtMed, 2006.

LÈVY, Pierre. Cibercultura. São Paulo, Ed.34, 1999.

LOIOLA, Rita. Geração Y. Revista Galileu n.219, out.2009. Disponível em http://revistagalileu.globo.com/Revista/Galileu/0,,EDG87165-7943-219,00GERACAO+Y.html. Acesso em 16 de julho de 2018.

MAURI, Teresa; ONRUBIA, Javier. A Incorporação das Tecnologias de Informação e Comunicação na Educação: Do projeto técnico-pedagógico às práticas de uso. In: COLL, César; MONEREO, Carles (Orgs.). Psicologia da Educação Virtual: 
Aprender e ensinar com as tecnologias da informação e comunicação. Porto Alegre: Artmed, 2010, p. 66- 96.

MONEREO, Carles; POZO, Juan Ignácio. O aluno em ambientes virtuais: condições, perfil e competências. In: In: COLL, Cesar; MONEREO, Carles. Psicologia da Educação Virtual: aprender e ensinar com as tecnologias da informação e Comunicação. Porto Alegre : Artmed, 20 pp.136-154.

MORIN, E. A cabeça bem feita: repensar a reforma, reformar o pensamento. Rio de Janeiro, Bertrand Brasil, 2011.

PERRENOUD, Philippe. Dez Novas Competências para Ensinar. Porto Alegre: Artmed Editora, 2000.

PIAGET, Jean. A epistemologia Genética. Petrópolis, Vozes, 1971.

PIOVESAN, Armando and TEMPORINI, Edméa Rita. Pesquisa exploratória: procedimento metodológico para o estudo de fatores humanos no campo da saúde pública. Rev. Saúde Pública [online]. 1995, vol.29, n.4, pp.318-325. ISSN 0034-8910. Acesso em 14 de julho de 2018.

PRENSKY, M. Digital Native, digital immmigrants. Digital Native immigrants. On the horizon, MCB University Press, Vol. 9, N.5, October, 2001. Disponível em: . Acesso em: 15 de julho de 2018.

SANTAELLA, L. Comunicação ubíqua: repercussões na cultura e na educação. São Paulo, Paulus, 2013.

SANTOS, E. O. Cibercultura: o que muda na educação. Entrevista ao programa Salto para o Futuro. TV Brasil. Disponível em < ROSEMARY SANTOS SANTOS; EDMÉA OLIVEIRA SANTOS http://tvbrasil.org.br/saltoparaofuturo/entrevista.asp?cod_Entrevista=119> Acesso em 6 de julho de 2018. 
SILVA, Marcos. O professor online e a pedagogia da transmissão. Disponível em: http://www.saladeaulainterativa.pro.br/texto_0002.htm. Acesso em 16 julho 2018.

VALENTE, J. Armando. (org.) Formação de Educadores para o uso da Informática na Escola. São Paulo : Editora UNICAMP, 2002.

VYGOTSKY, Lev. Pensamento e Linguagem. São Paulo: Martins Fontes, 1987.

ZABALA, Antoni. A prática educativa: como ensinar. Porto Alegre: Artmed Editora, 1998.

2. Linguagem de programação de inspiração piagetiana através da qual a criança aprende explorando seu ambiente.

3. IDC Brasil é uma empresa líder em inteligência de mercado, serviços de consultoria e conferências com as indústrias de Tecnologia da Informação e Telecomunicações. Disponível em < http://br.idclatin.com/>. Acesso em: 14 jul 2018.

4. Para o autor (p.54), apaixonado quer dizer consciente do prazer de aprender, não como acúmulo, mas como uma exploração permanente que questiona a realidade além das aparências e busca o sentido para interpretar o mundo e a própria atuação.

5. A Lei $n^{\circ} 4.131 / 2008$, do Distrito Federal, proíbe o uso de aparelhos celulares, bem como de aparelhos eletrônicos capazes de armazenar e reproduzir arquivos de áudio do tipo MP3, CD's e jogos, pelos alunos das escolas públicas e privadas do Distrito Federal, ao passo que em São Paulo há uma Lei (n 12.730/2007) que libera o uso do telefone celular para fins pedagógicos.

6. Os nativos digitais, segundo Prensky (2001), possuem a capacidade de realizar múltiplas tarefas, o que representa uma das características principais dessa geração. Ainda segundo esse autor, essa nova geração é formada, especialmente, por indivíduos que não se amedrontam diante dos desafios expostos pelas Tecnologias da Informação e da Comunicação (TIC) e experimentam e vivenciam múltiplas possibilidades oferecidas por novos aparatos digitais. 
7. Convergência ocorre quando tecnologias que eram anteriormente usadas de forma separada (voz, vídeo, dados, etc) passam a compartilhar o mesmo meio e interagem umas com as outras de forma sinergética, criando novas funcionalidades. (GABRIEL, 2013, p.80)

8. Dispositivos móveis são definidos como qualquer equipamento ou periférico que que pode ser transportado com informação que fique acessível em qualquer lugar. Ex: palms, laptops, tablets, pen drives e, certamente, os celulares multifuncionais. Por meio desses dispositivos, que cabem na palma de nossas mãos, à continuidade do tempo se soma a continuidade do espaço: a informação é acessível de qualquer lugar. (SANTAELLA, 2013)

Enviado: Agosto, 2019.

Aprovado: Agosto, 2019. 